\title{
The antibiotic checklist: an observational study of the discrepancy between reported and actually performed checklist items
}

\author{
Frederike V. van Daalen ${ }^{1 *}$, Marlies E. J. L. Hulscher ${ }^{2}$, Cas Minderhoud ${ }^{1}$, Jan M. Prins ${ }^{1}$ and Suzanne E. Geerlings ${ }^{1}$
}

\begin{abstract}
Background: Checklists are increasingly used to measure quality of care. Recently we implemented an antibiotic checklist in nine Dutch hospitals and showed that use of the checklist resulted in more appropriate antibiotic use. While more appropriate antibiotic use was associated with a reduction in length of stay, use of the checklist in itself was not. In the current study we explored discrepancies between reported and actually performed checklist items at the patient level to test the validity of checklist answers, to evaluate whether discrepancies between reported and actually performed checklist items could explain the lack of effect of checklist use on length of stay, and to identify missed opportunities for performance per checklist item.

Methods: Checklist answers represented reported performance. Actual performance was assessed by data from the patients' medical files. Reported and actually performed checklist items could be 'both YES'; 'both NO'; 'YES reported, NOT actually performed'; or 'NO reported, YES actually performed'. We determined an overall 'both YES' score per checklist, and used mixed models to evaluate whether an association existed between this overall score and patient's length of hospital stay. Finally, we analysed whether the items that were not actually performed, could have been performed.

Results: Between January and October 2015 physicians filled in 1207 checklists. In total 7881 items were checked. Most items were 'both YES' (3392/7881, 43.0\%) or 'both NO' (2601/7881, 33.0\%). The number of 'YES reported, NOT actually performed' items was 1628/7881 (20.7\%) compared to 260/7881 (3.3\%) 'NO reported, YES actually performed' items. The level of discrepancy between reported and actually performed items differed per checklist item. The item 'prescribe antibiotic treatment according to the local guideline' had the highest percentage of 'YES reported, NOT actually performed' items, namely $45.1 \%$. A higher overall 'both YES' score of the checklist was significantly associated with a shorter length of hospital stay. Of all checklist items $21.8 \%$ were not performed while they could have been performed.
\end{abstract}

Conclusions: Checklist answers do not accurately assess actual provided care. As actual performance of the antibiotic checklist items is associated with length of stay, efforts to increase actual performance appear to be justified.

Keywords: Checklists, Quality of care, Antibiotic management, Performance measures

\section{Background}

Checklists have been embraced in the medical field. Since the impressive success of the WHO surgical safety checklist in 2009 [1], more than 4000 hospitals worldwide implemented modified versions of this checklist [2]. In countries like the UK, Canada and the Netherlands, the Ministry of Health mandates the use of surgical safety

\footnotetext{
* Correspondence: f.v.vandaalen@amc.nl

${ }^{1}$ Department of Internal Medicine, Division of Infectious Diseases, Academic Medical Centre, University of Amsterdam, Room F4-132, Meibergdreef 9, 1105 AZ Amsterdam, the Netherlands

Full list of author information is available at the end of the article
}

checklists. Moreover, some policy makers apply "checklist use" as a measure for quality of care [3, 4].

Previously we developed and introduced an antibiotic checklist to improve the quality of antibiotic use by reminding physicians of the most important steps in recommended appropriate antibiotic use $[5,6]$. Such improvement is not only necessary to curb antimicrobial resistance, but has also been associated with various patient outcomes, including reduced length of hospital stay [7-10]. In our study, use of the antibiotic checklist resulted in more appropriate antibiotic use. We found that 
more appropriate antibiotic use was significantly associated with a shorter length of hospital stay for the patient. However, use of the checklist in itself was not associated with a reduction in length of stay [6]. One probable explanation for these contradictory results could be that 'completing a checklist' and 'actual performance of the checklist items' are in practice not the same.

Although previous studies have suggested that variation in actual compliance with checklists exists [2, $11,12]$, so far this has not been illustrated with data at patient level. In the current study we explored discrepancies between reported and actually performed checklist items at the patient level to test the validity of checklist answers, to evaluate whether discrepancies between reported and actually performed checklist items could explain the lack of effect of checklist use on length of hospital stay in the clinical trial, and to identify missed opportunities for performance per checklist item.

\section{Methods}

\section{Study design and setting}

This observational study was performed alongside a stepped wedge cluster randomised trial evaluating the effectiveness of introducing an antibiotic checklist [6]. Patients were included in two university- and seven teaching hospitals in the Netherlands between January and October 2015. In each hospital at least one surgical, one non-surgical, and the emergency department participated.

\section{Appropriate antibiotic use - The antibiotic checklist}

The antibiotic checklist was meant as a supporting tool to remind physicians of the most important steps in recommended appropriate antibiotic use [6]. It consisted of seven generic quality indicators that define appropriate antibiotic use in the hospital (Additional file 1: Figure S1) $[13,14]$. The checklist was divided into two bundles. The first bundle (five items) had to be completed at the moment of prescribing IV antibiotics. The second bundle (two items) had to be used during the course of treatment, at the latest after $72 \mathrm{~h}$ of treatment. A barrier survey was performed prior to checklist introduction to optimize its usability in daily practice [5]. One result of this survey was that $17.4 \%$ of the physicians thought the checklist was too complex for use in daily practice. Therefore we adapted the checklist by including tickboxes and pre-printed options. For each item on the checklist it was possible to choose the answer "YES" or "NO". If "NO" was checked, physicians could indicate the reason for this decision. For example, therapy could not be adapted based on culture result because a positive culture result was lacking.
Physicians completed the checklists for hospitalized adults ( $\geq 18$ years old) or adults at the emergency department who were admitted at a participating ward with a suspected community-acquired and/or hospital-acquired bacterial infection and were prescribed intravenous antibiotics. The participants were both residents and specialists with different levels of experience. One month preceding the start of checklist use in each hospital, introduction of the antibiotic checklist was prepared. The checklists were displayed in printed form at all working places at the participating departments. Stimulating activities to use the checklist, such as education, feedback and reminders, were organised. It was the physicians' responsibility to use the checklist each time an antibiotic was started. Physicians were informed that the effect of checklist use on the appropriateness of antibiotic use and on length of hospital stay would be measured. They did not know that their answers on the checklist would be checked against the electronic medical records.

\section{Assessments}

We included checklists used for eligible patients with at least one item checked. [6] The answers ticked on the checklist represented the reported performance of the item at patient level. The arguments for nonperformance that were reported by the physician on the completed checklist were defined as 'reasons for nonperformance'.

Actual performance of the checklist items was assessed by collection of data from the patients' electronic medical records (EMR), including medication charts and laboratory results. Data were recorded on the collection of blood cultures, the collection of cultures of suspected sites of infection, antibiotic use including dosage, route of administration and duration of treatment, relevant laboratory parameters, suspected type of infection and, if relevant, changes in diagnosis.

\section{Analysis}

The ticks on the checklist directly assessed the reported performance. For the actual performance, the data of the patients' EMRs were evaluated using previously developed algorithms. ${ }^{14}$ For example -concerning the checklist item 'prescribe antibiotic treatment according to the local guideline'- when a patient was treated with ceftriaxone because of a suspected community-acquired pneumonia, an algorithm determined whether that treatment was according to the local guideline.

Per checklist item we determined the concordance between reported performance and actual performance. We distinguished positive ("YES") and negative ("NO") answers. Reported and actually performed checklist items could be: 
1) Both YES. E.g., both the checklist answer "YES, I prescribe antibiotic treatment according to the local guideline" and the algorithm indicated that the antibiotic treatment was according to the local guideline;

2) Both NO. E.g., both the checklist answer "NO, I do not prescribe antibiotic treatment according to the local guideline" and the algorithm indicated that the antibiotic treatment was not according to the local guideline;

3) YES reported, NOT actually performed. E.g., the checklist answer "YES, I prescribe antibiotic treatment according to the local guideline" indicated that antibiotics were prescribed according to the guideline, while the algorithm indicated that the antibiotic treatment was not according to the local guideline;

4) NO reported, YES actually performed. E.g., the checklist answer "NO, I do not prescribe antibiotic treatment according to the local guideline" indicated that antibiotics were not prescribed according to the guideline, while the algorithm indicated that the antibiotic treatment was according to the local guideline.

First we determined the validity of the checklist answers. The items 'YES reported, NOT actually performed' and 'NO reported, YES actually performed' indicated differences between reported and actual performance. Both items disrupted the validity of the reported checklist answers. In case of 'YES reported, NOT actually performed' the reported checklist answer gave an overestimation of actually provided care, while in case of 'NO reported, YES actually performed' the reported checklist answer gave an underestimation of actually provided care.

Previous studies showed an association between actual performance of the checklist items and a shorter length of hospital stay. $[6,15]$ In the clinical trial we saw that completing the antibiotic checklist was not associated with a reduction in length of stay [6], suggesting that 'actual performance of checklist items' is not the same as 'checklist completion'. To evaluate whether these differences could explain the lack of effect on length of hospital stay in the clinical trial, we investigated if patients in whom a checklist was used and the items were actually performed had a shorter length of stay compared to patients in whom checklist use did not lead to actual performance of the items. To do so, we calculated an overall 'both YES' score per checklist. This score expressed the total number of 'both YES' items on that particular checklist (maximum of 7). We distinguished very low ( $\leq 1$ 'both YES' items), low (2 'both YES' items), medium (3 'both YES' items), high (4 'both YES' items) and very high ( $\geq 5$ 'both YES' items) overall scores. We evaluated whether an association existed between the overall 'both YES' score and the geometric mean of length of hospital stay of the patients.

For all not actually performed items we determined the applicability to the particular patient using algorithms [14]. A 'missed opportunity for performance' was a checklist item that was not actually performed while it could have been performed according to the algorithm, independently of the answer on the checklist. E.g., the item "adapt dosage to renal function" only applied to patients with a declined renal function and treatment with an antibiotic of which dosage adjustment was required. The algorithm took these parameters into account to determine the applicability. When "adapt dosage to renal function" applied to the patient, but the item was not actually performed, a missed opportunity for performance was indicated. We evaluated how often these missed opportunities for performance occurred per checklist item. In this evaluation we distinguished items in which the non-performance was reported (thus, 'both NO' items) and items in which the nonperformance was not reported (thus, 'YES reported, NOT actually performed' items). We also performed an in-depth analysis of all items with a missed opportunity for performance, in which we determined when or why the physicians did not actually perform the item while it could have been performed.

The study was exploratory and therefore we used mainly descriptive measures. Frequencies of 'both YES', 'both NO, 'YES reported, NOT actually performed' and 'NO reported, YES actually performed' items were expressed in absolute numbers and percentages. The association between overall 'both YES' scores and length of hospital stay was evaluated using generalised linear mixed models. These models account for within-cluster dependencies, which is required as checklists from nine different hospitals were included. Furthermore, the models adjust for possible confounders, which is necessary because in the clinical trial several covariates appeared to influence length of stay. We included the hospitals (clusters) as a random effect, and patient and treatment characteristics -age, comorbidity, type of diagnosis, community vs hospital acquired infection, antibiotics started at the Emergency Department versus ward [6]- as fixed effects in the mixed model analysis. $P<0.05$ was considered statistically significant. Analyses were done using IBM SPSS Statistics, version 23.0.

\section{Results}

In 1207 of the 5354 eligible patients a checklist was used (22.5\%). Of the 1207 included checklists 993 (82.3\%) were fully and $214(17.7 \%)$ were partly completed. In total 7881 checklist items were checked. 
Figure 1 shows the number of reported and actually performed checklist items. Most items were 'both YES' (3392/7881, 43.0\%) or 'both NO' (2601/7881, 33.0\%). The number of 'YES reported, NOT actually performed' items was 1628/7881 (20.7\%) compared to 260/7881 (3.3\%) 'NO reported, YES actually performed' items. Thus, overall, the reported checklist answers gave an overestimation of the actually provided care.

The level of concordance between reported and actually performed items differed per checklist item (Table 1). Items were most often 'both YES' for 'documentation of indication' (90.4\%), and most often 'both NO' for 'adapt dose to renal function' (72.9\%). The percentage of 'YES reported, NOT actually performed' items was remarkably high for 'prescribe antibiotic treatment according to the local guideline', namely $45.1 \%$. The percentage of 'NO reported, YES actually performed' items was low for all checklist items.

Figure 2 presents the association between the overall 'both YES' scores of checklists and the geometric mean of length of hospital stay of the patients. Patients with more 'both YES' items - YES the checklist item was reported and YES the checklist item was actually performed - had a significantly shorter length of hospital stay compared to patients with less 'both YES' items on the checklist.

Figure 1 also illustrates how often the items that were not actually performed, could have been performed. In 999/1628 of the 'YES reported, NOT actually performed' items (61.4\%) the item applied to the patient, indicating that 999 opportunities for performance were missed. Most opportunities for performance were missed for guideline adherence (Fig. 1).

Table 2 presents the most common causes of discrepancy between reported and actual performance in these 999 items. For example, the majority of the patients with a 'YES reported, NOT actually performed' item for 'culture from suspected site of infection' were diagnosed with a respiratory tract infection (86/138 patients (62\%)), whereas only nine patients (7\%) were diagnosed with a urinary tract infection.

Of all 'both NO' items, $25.1 \%$ could have been performed according to the algorithms (654/2601) (Figure 1). The most opportunities for performance were missed on the checklist item 'take two sets of blood cultures', namely 19.0\% (228/1202).

The reasons physicians reported on the checklists for non-performance in case of 'both NO' items are presented in Table 3 . This table illustrates that physicians' opinions can be contrary to the algorithms [14]. For example, in 32 patients physicians reported that switching intravenous to oral treatment could not be performed because of 'insufficient clinical improvement', while according to the algorithm which was based on criteria for a safe early switch $-[14,16]$, the clinical improvement was sufficient for switching to oral therapy.

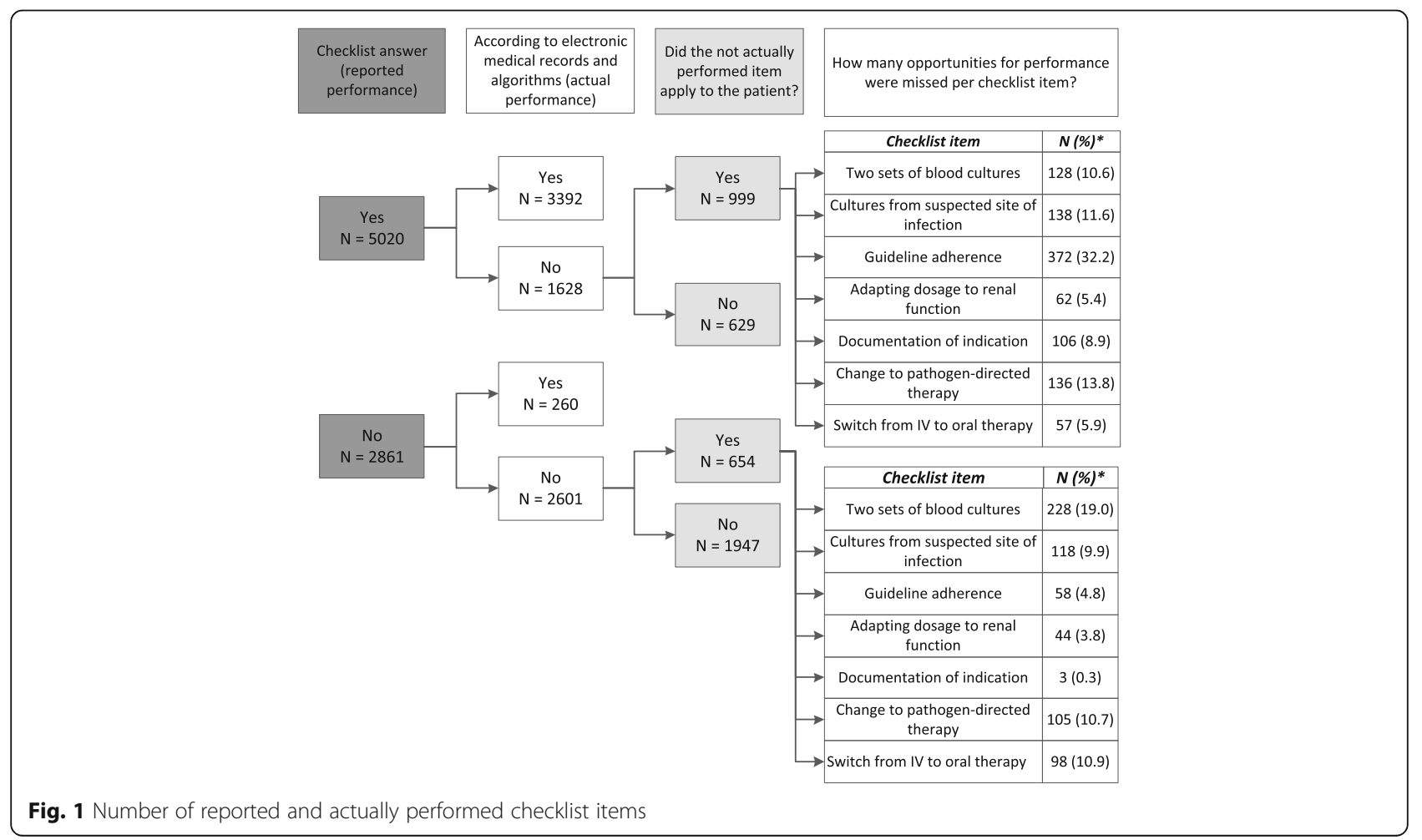


Table 1 Concordance per checklist item

\begin{tabular}{|c|c|c|c|c|c|}
\hline Checklist item & $\begin{array}{l}\text { Both YES } \\
\text { (\% of all answers for } \\
\text { this checklist item) }\end{array}$ & $\begin{array}{l}\text { Both } \mathrm{NO}^{\mathrm{a}} \\
\text { (\% of all answers for } \\
\text { this checklist item) }\end{array}$ & $\begin{array}{l}\text { YES reported, NOT } \\
\text { actually performed } \\
\text { (\% of all answers for } \\
\text { this checklist item) }\end{array}$ & $\begin{array}{l}\text { NO reported, YES } \\
\text { actually performed } \\
\text { (\% of all answers for } \\
\text { this checklist item) }\end{array}$ & $\begin{array}{l}\text { Total number of answers } \\
\text { for this checklist item }{ }^{a}\end{array}$ \\
\hline Blood cultures & $784(65.2)$ & $228(19.0)$ & $128(10.6)$ & $62(5.2)$ & $1202(100)$ \\
\hline $\begin{array}{l}\text { Cultures from suspected } \\
\text { site of infection }\end{array}$ & $571(47.9)$ & $417(35.0)$ & $173(14.5)$ & $30(2.5)$ & $1191(100)$ \\
\hline Guideline adherence & $483(40.4)$ & $116(9.7)$ & $540(45.1)$ & $58(4.8)$ & $1197(100)$ \\
\hline $\begin{array}{l}\text { Adapt dose to renal } \\
\text { function }\end{array}$ & $66(5.7)$ & $841(72.9)$ & $223(19.3)$ & $24(2.1)$ & $1154(100)$ \\
\hline $\begin{array}{l}\text { Documentation of } \\
\text { indication }\end{array}$ & $1076(90.4)$ & $3(0.3)$ & $106(8.9)$ & $5(0.4)$ & $1190(100)$ \\
\hline $\begin{array}{l}\text { Adapt therapy when } \\
\text { cultures become available }\end{array}$ & $126(12.8)$ & $556(56.5)$ & $253(25.7)$ & $49(5.0)$ & $984(100)$ \\
\hline IV-oral switch & $286(29.7)$ & $440(45.7)$ & $205(21.3)$ & $32(3.3)$ & $963(100)$ \\
\hline
\end{tabular}

${ }^{a}$ numbers are $\mathrm{N}(\%)$

\section{Discussion}

In this study we have illustrated a discrepancy between reported and actually performed appropriate antibiotic use as captured by the checklist items of the antibiotic checklist in the hospital. Approximately 21\% of all items were reported while not actually performed, giving an overestimation of actually provided care. Patients with more reported and actually performed ('both YES') items had a shorter length of hospital stay compared to patients with less 'both YES' items. This association is in line with previous results $[10,15]$, which supports the suggestion that discordance between reported and actual performance has disrupted the impact of the checklist on length of stay. In total $1653(999+654)$ items were not performed while they could have been performed according to the algorithms, suggesting missed opportunities for performance.

Since $21 \%$ of all reported items gave an overestimation of actually provided care, the antibiotic checklist cannot be considered a valid instrument to measure provided quality of care. Although much less detailed than in our study, the existence of discrepancy between reported and actual performance has been described previously $[2,17-20]$. For example, the time-out section of the Surgical Safety Checklist was actually performed as intended in $38.5 \%$ of the 294 observed operations in the UK while claimed to have been done in more than $95 \%$ of these operations by one team member (most often the scrub nurse) at the operation room [17].

According to our algorithms, 1653 opportunities for performance were missed, indicating room for improvement of performance. Several studies reported the room for improvement on performance per checklist item for (parts of) the Surgical Safety Checklist [2, 1719, 21-23]. This room was considerable and varied between 3 and $100 \%$ per checklist item. In our study the room for improvement of performance varied between 9

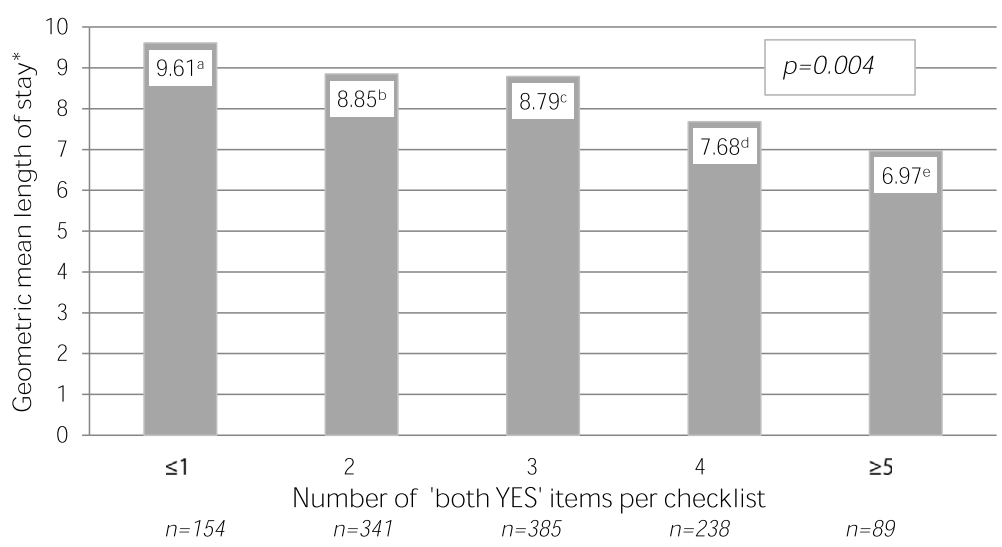

Fig. 2 Association between the overall 'both YES' scores of the checklists and length of hospital stay. Legends:*after correction for the same covariates as in the clinical trial [6], namely: age, comorbidity, type of diagnosis, community- versus hospital-acquired infection and antibiotics started at the Emergency Department versus ward, ${ }^{a} 95 \%$ confidence interval $8.41-11.13,{ }^{\text {b }}$ 95\% confidence interval $7.24-8.67,{ }^{c}$ 95\% confidence interval $6.62-7.92,{ }^{d} 95 \%$ confidence interval $5.21-6.36,{ }^{e} 95 \%$ confidence interval $4.31-5.70$ 
Table 2 Overview of situations in which physicians did not actually perform a checklist item which could have been performed

\begin{tabular}{|c|c|c|c|}
\hline Checklist item & $\begin{array}{l}\text { 'YES reported, NOT } \\
\text { actually performed' } \\
\text { while checklist item } \\
\text { applied to the patient }(\mathrm{N})\end{array}$ & Information about actual performance & $\begin{array}{l}N \\
(\%)\end{array}$ \\
\hline $\begin{array}{l}\text { Take at least two } \\
\text { sets of blood cultures before starting } \\
\text { systemic antibiotic therapy }\end{array}$ & 128 & $\begin{array}{l}\text { Only one set of blood cultures } \\
\text { was performed }\end{array}$ & $110(86)$ \\
\hline \multirow[t]{3}{*}{$\begin{array}{l}\text { Take specimens for cultures from } \\
\text { suspected sites of infection }\end{array}$} & \multirow[t]{3}{*}{138} & $\begin{array}{l}\text { Diagnosis was a respiratory tract } \\
\text { infection, sputum culture was } \\
\text { not performed }\end{array}$ & $86(62)$ \\
\hline & & $\begin{array}{l}\text { Two possible diagnoses were } \\
\text { recorded, only one culture } \\
\text { was performed }\end{array}$ & $35(25)$ \\
\hline & & $\begin{array}{l}\text { Diagnosis was a urinary tract } \\
\text { infection, urine culture was } \\
\text { not performed }\end{array}$ & $9(7)$ \\
\hline \multirow[t]{4}{*}{$\begin{array}{l}\text { Prescribe systemic antibiotic treatment } \\
\text { according to the local guideline }\end{array}$} & \multirow[t]{4}{*}{372} & $\begin{array}{l}\text { Antibiotic treatment for a } \\
\text { respiratory tract infection } \\
\text { not according to the guidelines }\end{array}$ & $123(33)$ \\
\hline & & $\begin{array}{l}\text { Antibiotic treatment for two } \\
\text { diagnoses one or both not } \\
\text { according to the guidelines }\end{array}$ & $68(18)$ \\
\hline & & $\begin{array}{l}\text { Antibiotic treatment for a } \\
\text { urinary tract infection not } \\
\text { according to the guidelines }\end{array}$ & $64(17)$ \\
\hline & & $\begin{array}{l}\text { Antibiotic treatment for a } \\
\text { skin infection not according } \\
\text { to the guidelines }\end{array}$ & $40(11)$ \\
\hline \multirow{3}{*}{$\begin{array}{l}\text { Adapt dose and dosing interval of systemic } \\
\text { antibiotics to renal function }\end{array}$} & \multirow[t]{3}{*}{62} & No adaption while eGFR $<10$ mL/min & $7(11)$ \\
\hline & & No adaption while eGFR $10-30$ mL/min & $37(60)$ \\
\hline & & No adaption while eGFR $30-50$ mL/min & $18(29)$ \\
\hline $\begin{array}{l}\text { Document the indication for antibiotic } \\
\text { treatment in the case notes or electronic } \\
\text { medical record (EMR) }\end{array}$ & 106 & No documentation & $106(100)$ \\
\hline \multirow{2}{*}{$\begin{array}{l}\text { Adapt therapy when culture results } \\
\text { become available }\end{array}$} & \multirow[t]{2}{*}{136} & Change took place on the fourth day of therapy & $34(25)$ \\
\hline & & Change took place on the fifth day of therapy & $8(6)$ \\
\hline \multirow{2}{*}{$\begin{array}{l}\text { Switch from intravenous to oral antibiotic } \\
\text { therapy after } 48-72 \mathrm{~h}\end{array}$} & \multirow[t]{2}{*}{57} & Switch was performed on the fourth day of therapy & $27(47)$ \\
\hline & & Switch was performed on the fifth day of therapy & $11(19)$ \\
\hline
\end{tabular}

and $41 \%$ per checklist item, with most missed opportunities for prescribing antibiotic treatment according to the local guideline. In the majority of these items performance was reported while not actually done. We do not know whether physicians were aware of the discrepancies between reported and actually performed items. It has been noticed before that the perception of physicians of their performance is higher than actual performance [2, 18, 24]. For example, an analysis of physicians' perceptions on antimicrobial use illustrated that most physicians agreed that antibiotics are overprescribed, but only a small proportion felt that they themselves overprescribed [24].

The second item with a relatively high percentage of missed opportunities for performance was the performance of two sets of blood cultures. The majority of these items were 'both NO' (not reported and not actually performed), meaning that the physician intentionally did not perform blood cultures. The common explanation for non-performance (84 times) was that the physician thought blood culture performance was not necessary with the suspected diagnosis. In our barrier study several physicians already mentioned these doubts, wherefore we added the option "In my opinion, not necessary with this diagnosis" in the checklist [5]. Although in an international Delphi procedure taking blood cultures was considered a quality indicator for appropriate antibiotic use in all hospitalized patients with intravenous antibiotic treatment $[6,13,14]$, the clinical relevance of blood cultures in some diagnoses has been questioned [25], and the finding that this answer option was often used in our study, suggests that taking blood cultures 
Table 3 Reported reasons for non-performance of an applicable checklist item

\begin{tabular}{|c|c|c|}
\hline Checklist item & $\begin{array}{l}\text { Given argument by the physician who completed the checklist for } \\
\text { non-performance of the checklist item }\end{array}$ & Number \\
\hline \multirow{13}{*}{$\begin{array}{l}\text { Take at least two sets of blood cultures before starting } \\
\text { systemic antibiotic therapy }\end{array}$} & In my opinion, blood culturesare not necessary with this diagnosis & 84 \\
\hline & Only one set performed instead of two (without explanation) & 45 \\
\hline & No indication for blood culture performance because the patient has no fever & 25 \\
\hline & Unclear why blood cultures are not performed by my colleague & 24 \\
\hline & Only one set performed at the emergency department & 10 \\
\hline & No reason given & 10 \\
\hline & Only one set performed because phlebotomy was difficult & 7 \\
\hline & $\begin{array}{l}\text { No indication for blood culture performance because the antibiotics } \\
\text { are prophylactic }\end{array}$ & 6 \\
\hline & $\begin{array}{l}\text { No indication for blood culture performance because antibiotic } \\
\text { treatment is based on previous culture result }>1 \text { week ago }\end{array}$ & 4 \\
\hline & We only perform cultures from suspected site of infection & 3 \\
\hline & $\begin{array}{l}\text { No time to perform blood cultures because of critical clinical } \\
\text { condition of the patient }\end{array}$ & 2 \\
\hline & Other & 8 \\
\hline & Total & 228 \\
\hline \multirow[t]{8}{*}{ Take specimens for cultures from suspected sites of infection } & No culture possible from suspected site of infection & 79 \\
\hline & No sputum production with a suspected respiratory tract infection & 19 \\
\hline & Not done (without explanation) & 5 \\
\hline & Culture performance will follow later & 4 \\
\hline & $\begin{array}{l}\text { Forgotten to perform cultures from suspected site of infection } \\
\text { before start of therapy }\end{array}$ & 3 \\
\hline & No reason given & 3 \\
\hline & Other & 5 \\
\hline & Total & 118 \\
\hline \multirow{9}{*}{$\begin{array}{l}\text { Prescribe systemic antibiotic treatment according to } \\
\text { the local antibiotic guideline }\end{array}$} & No reason given & 22 \\
\hline & Following other guidelines & 7 \\
\hline & Several possible diagnoses: it is notclear which guideline should be followed & 5 \\
\hline & We deviate fromlocal guidelines after consulting microbiologist & 4 \\
\hline & Antibiotic treatment is based on previous antibiotic therapy & 4 \\
\hline & $\begin{array}{l}\text { We deviate fromlocal guidelines because mysupervisor prefers another } \\
\text { antibiotic }\end{array}$ & 3 \\
\hline & $\begin{array}{l}\text { Gentamycin should be given according to the local guidelines, however } \\
\text { we did not prescribe gentamycin since the patient is not septic }\end{array}$ & 2 \\
\hline & Other & 11 \\
\hline & Total & 58 \\
\hline \multirow{6}{*}{$\begin{array}{l}\text { Adapt dose and dosing interval of systemic antibiotics } \\
\text { to renal function }\end{array}$} & This quality indicator is not applicable to this patient & 38 \\
\hline & No reason given & 3 \\
\hline & Peritoneal dialysis & 1 \\
\hline & eGFR just below normal: expectation that renal function will improve quickly & 1 \\
\hline & Renal function not known & 1 \\
\hline & Total & 44 \\
\hline \multirow{3}{*}{$\begin{array}{l}\text { Document the indicationfor the antibiotictreatment in the } \\
\text { case notes or electronic medical record (EMR) }\end{array}$} & No reason given & 1 \\
\hline & Fever of unknown origin, and thus we do not know what to document & 1 \\
\hline & $\begin{array}{l}\text { Cefuroxime is started at the emergency department but the indication is } \\
\text { not clearly explained }\end{array}$ & 1 \\
\hline
\end{tabular}


Table 3 Reported reasons for non-performance of an applicable checklist item (Continued)

\begin{tabular}{|c|c|c|}
\hline Checklist item & $\begin{array}{l}\text { Given argument by the physician who completed the checklist for } \\
\text { non-performance of the checklist item }\end{array}$ & Number \\
\hline & Total & 3 \\
\hline \multirow[t]{9}{*}{ Adapt therapy when culture results become available } & No culture result (yet) & 46 \\
\hline & No reason given & 18 \\
\hline & Pathogen is susceptible to the current antibiotic treatment & 15 \\
\hline & Treatment based on clinical condition & 9 \\
\hline & Several pathogens are cultured: doubts about relevance & 4 \\
\hline & Treatment was already started based on culture results & 3 \\
\hline & Treatment chosen after consulting microbiologist & 2 \\
\hline & Other & 8 \\
\hline & Total & 105 \\
\hline \multirow{13}{*}{$\begin{array}{l}\text { Switch from intravenous to oral antibiotic } \\
\text { therapy after } 48-72 h\end{array}$} & Insufficient clinical improvement & 32 \\
\hline & No oral antibiotic available & 16 \\
\hline & No oral therapy possible with this diagnosis & 14 \\
\hline & Antibiotic treatment is stopped & 8 \\
\hline & Continue IV (without explanation) & 7 \\
\hline & Prefer to treat five days intravenously & 5 \\
\hline & No adequate oral intake/gastrointestinal absorption & 3 \\
\hline & No reason given & 4 \\
\hline & Unclear diagnosis and unclear to which antibiotic should be switched & 3 \\
\hline & No culture results & 3 \\
\hline & After consulting microbiologist & 2 \\
\hline & Allergy & 1 \\
\hline & Total & 98 \\
\hline Total & & 654 \\
\hline
\end{tabular}

might not be agreed-upon standard practice. This should be taken into account for future checklist use, as disagreement about the contents of an intervention makes it very unlikely that it will be successful [26].

Our study has several strengths. To our knowledge, our study is the first to evaluate the discordancy between reported and actually performed checklist items by using the ticks on the box reported by the physician him- or herself at the moment of performance. These data provide very detailed information per checklist item on the physicians' perception of their own performances. Additionally we provided information about physicians' considerations for resigning from recommended antibiotic care. We included a large number of checklists collected in nine representative Dutch hospitals. Finally, we illustrated that this in-depth analysis can help to better understand other results, such as, in our study, the lack of effect of checklist use on length of stay. Our findings are very relevant, since checklists are increasingly used to measure quality of care $[3,4]$, with sometimes consequences for the reimbursement of this care. This study showed that checklist use is not equal to actual performance of checklist items and therefore checklists cannot be considered a valid instrument to measure provided quality of care.

Our study also has limitations. We did not include the overall completion rate in this evaluation. As in the majority of the eligible patients in the clinical trial a checklist was not used (77.5\%) [6], it is possible that the (partially) completed checklists were filled in by physicians who were motivated to improve the quality of their antibiotic care, resulting in a certain selection bias. On the other hand, when physicians are forced to fill in checklists, discrepancies may even be higher. Another limitation could be that the actual performance was based on documentation in the EMRs and not on direct observations. However, due to extensive search in all sources available, including the laboratory results and medication charts, we think this data reliably reflects actually performed items.

The general limitation of algorithms is that they can do injustice to the complexity of patient care and clinical judgement [27]. For example, we know from clinical practice that obtaining a sputum culture can 
be challenging in practice, resulting in more nonperformed items despite the intention (YES reported) of performance (Table 2). Likewise, as illustrated in Table 3, sometimes physicians had valid reasons for non-performance of checklist items in our study. For example, deviating from local guidelines after consulting a microbiologist is most likely in favour of patient care. Therefore performance scores of $100 \%$ are unrealistic and even undesirable.

In future research the economic perspectives of using the antibiotic checklist should be considered. When the checklist is further implemented, the indicated missed opportunities for performance can guide local antibiotic stewardship teams in designing interventions. For example, 123 items were 'YES reported, NOT actually performed' for 'prescribing antibiotic treatment according to the local guideline' while the suspected diagnosis was a respiratory infection, and so education about the guidelines for respiratory tract infections could be considered. Likewise, since in 110 of the 'YES reported, NOT actually performed' items of 'two sets of blood cultures' only one set was performed, the importance of taking two sets of blood cultures should be emphasized [28]. Building the checklist into the EMR could also improve actual performance of checklist items. Integration of the Surgical Safety Checklist in the EMR resulted in a significant increase in checklist compliance [29].

\section{Conclusion}

In conclusion, the antibiotic checklist should be used as a supporting tool, not as an instrument to measure actual provided care. As actual performance of the antibiotic checklist items was associated with the patients' length of hospital stay, efforts to increase actual performance appear to be justified.

\section{Additional file}

Additional file 1: The antibiotic checklist. (PDF 207 kb)

\section{Abbreviations}

EMR: Electronic Medical Record

\section{Acknowledgements}

We thank all physicians who participated in the clinical trial, including the staff and residents of the Antonius ziekenhuis Nieuwegein, Flevoziekenhuis Almere, Onze Lieve Vrouwe Gasthuis Amsterdam, Reinier de Graaf Delft, Spaarnegasthuis Hoofddorp, Spaarnegasthuis Haarlem, VU Medical Centre Amsterdam, Westfriesgasthuis Hoorn and the Academic Medical Centre Amsterdam.

\section{Funding}

This study is funded by the Netherlands Organisation for Health Research and Development (ZonMw) grant 836,021,001.

\section{Availability of data and materials}

The datasets used and analysed during the current study are available from the corresponding author on reasonable request.

\section{Authors' contributions}

SEG, JMP and MEJLH coordinated the application for funding. FVD, SEG and MEJLH were involved in the conception of the study. FVD and CM performed the analyses. All authors read and approved the final version of the manuscript.

\section{Ethics approval and consent to participate}

The Medical Ethics Research Committee of the Academic Medical Centre confirmed that the Medical Research Involving Human Subjects Act did not apply to this study project. Individual informed consent was waived for all participating hospitals, including Antonius ziekenhuis Nieuwegein,

Flevoziekenhuis Almere, Onze Lieve Vrouwe Gasthuis Amsterdam, Reinier de Graaf Delft, Spaarnegasthuis Hoofddorp, Spaarnegasthuis Haarlem, VU Medical Centre Amsterdam, Westfriesgasthuis Hoorn and the Academic Medical Centre Amsterdam. Each hospital's board of directors approved the study protocol. The clinical trial was registered with the Dutch Trial Registry, number NTR4872.

\section{Consent for publication}

Not applicable.

\section{Competing interests}

The authors declare that they have no competing interests.

\section{Publisher's Note}

Springer Nature remains neutral with regard to jurisdictional claims in published maps and institutional affiliations.

\section{Author details}

${ }^{1}$ Department of Internal Medicine, Division of Infectious Diseases, Academic Medical Centre, University of Amsterdam, Room F4-132, Meibergdreef 9, 1105 AZ Amsterdam, the Netherlands. ${ }^{2}$ Radboud Institute for Health Sciences, Radboud University Medical Center, Nijmegen, the Netherlands.

Received: 8 August 2017 Accepted: 3 December 2017

Published online: 08 January 2018

\section{References}

1. Haynes AB, Weiser TG, Berry WR, et al. Safe surgery saves lives study group. A surgical safety checklist to reduce morbidity and mortality in a global population. N Engl J Med. 2009;360:491-9.

2. Levy SM, Senter $\mathrm{CE}$, Hawkins RB, et al. Implementing a surgical checklist: more than checking a box. Surgery. 2012;152:331-6.

3. Patient Safety. Toronto: Ontario Ministry of Health and Long Term Care. http://www.health.gov.on.ca/en/public/programs/patient_safety. Accessed 7 Aug 2017

4. Public reporting - patient safety: percent of surgeries in which a surgical safety checklist was used. http://www.hqontario.ca/System-Performance/ Hospital-Care-Sector-Performance. Accessed 7 Aug 2017.

5. Van Daalen FV, Geerlings SE, Prins JM, Hulscher MEJL. A survey to identify barriers of implementing an antibiotic checklist. Eur J Clin Microbiol Infect Dis. 2016;35:545

6. Van Daalen FV, Prins JM, Opmeer BC, Boermeester MA, Visser CE, van Hest RM, et al. The effect of an antibiotic checklist on length of hospital stay and appropriate antibiotic use in adult patients treated with intravenous antibiotics: a stepped wedge cluster randomised trial. Clinical Microbiol Infect. 2017;23:485.e1-8.

7. Schuts EC, Hulscher ME, Mouton JW, Verduin CM, Stuart JW, Overdiek HW et al. Current evidence on hospital antimicrobial stewardship objectives: a systematic review and meta-analysis. Lancet Infect Dis. 2016;16:847-56.

8. McCabe C, Kirchner C, Zhang H, Daley J, Fisman DN. Guideline-concordant therapy and reduced mortality and length of stay in adults with community-acquired pneumonia. Arch Intern Med. 2009;169:1525-31.

9. Davey P, Marwick CA, Scott CL, Charani E, McNeil K, Brown E, et al. Interventions to improve antibiotic prescribing practices for hospital inpatients. Cochrane Database Syst Rev. 2017;9:CD003543. 
10. Spoorenberg V, Hulscher ME, Akkermans RP, Prins JM, Geerlings SE. Appropriate antibiotic use for patients with urinary tract infections reduces length of hospital stay. Clin Infect Dis. 2014;58:164-9.

11. Urbach DR, Govindarajan A, Saskin R, Wilton AS, Baxter NN. Introduction of surgical safety checklists in Ontario. Canada N Engl J Med. 2014;370: 1029-38.

12. Van Klei WA, Hoff RG, van Aarnhem EE, Simmermacher RK, Regli LP, Kappen $\mathrm{TH}$, et al. Effects of the introduction of the WHO "surgical safety checklist" on in-hospital mortality: a cohort study. Ann Surg. 2012;255:44-9.

13. Van den Bosch CM, Geerlings SE, Natsch S, Prins JM, Hulscher MEJL. Quality indicators to measure appropriate antibiotic use in hospitalized adults. Clin Infect Dis. 2015;60:281-91.

14. van den Bosch CM, Hulscher ME, Natsch S, Wille J, Prins JM, Geerlings SE. Applicability of generic quality indicators for appropriate antibiotic use in daily hospital practice: a cross-sectional point-prevalence multicenter study. Clinical Microbiol Infect. 2016;22:888.e1-9.

15. van den Bosch CM, Hulscher MEJL, Akkermans RP, Wille J, Geerlings SE, Prins JM. Appropriate antibiotic use reduces length of hospital stay. J Antimicrob Chemother. 2017;72:923-32.

16. Sevinç F, Prins JM, Koopmans RP, Langendijk PN, Bossuyt PM, Dankert J, et al. Early switch from intravenous to oral antibiotics: guidelines and implementation in a large teaching hospital. J Antimicrob Chemother. 1999; 43:601-6.

17. Pickering SP, Robertson ER, Griffin D, Hadi M, Morgan LJ, Catchpole KC, et al. Compliance and use of the World Health Organization checklist in UK operating theatres. Br J Surg. 2013;100:1664-70.

18. Sendlhofer G, Lumenta DB, Leitgeb K, Kober B, Jantscher L, Schanbacher M, et al. The gap between individual perception and compliance: a qualitative follow-up study of the surgical safety checklist application. PLoS One. 2016; 11:e0149212.

19. Sparks EA, Wehbe-Janek H, Johnson RL, Smythe WR, Papaconstantinou HT. Surgical safety checklist compliance: a job done poorly! J Am Coll Surg. 2013:217:867-73.

20. Salgado D, Barber KR, Danic M. Objective assessment of checklist Fidelity using digital audio recording and a standardized scoring system audit. J Patient Saf. 2016; https://doi.org/10.1097/PTS.0000000000000306.

21. Biffl WL, Gallagher AW, Pieracci FM, Berumen C. Suboptimal compliance with surgical safety checklist in Colorado: a prospective observational study reveals differences between surgical specialties. Patient Saf Surg. 2015;9:5.

22. Van Schoten SM, Kop V, de Blok C, Spreeuwenberg P, Groenewegen PP, Wagner C. Compliance with a time-out procedure intended to prevent wrong surgery in hospitals: results of a national patient safety programme in the Netherlands. BMJ Open. 2014;4:e005075.

23. Rydenfält C, Johansson G, Odenrick P, Akerman K, Larsson PA. Compliance with the surgical safety checklist: deviations and possible improvements. Int J Qual Health Care. 2013:25:182-7.

24. Abbo L, Sinkowitz-Cochran R, Smith L, Ariza-Heredia E, Gómez-Marín O, Srinivasan A, et al. Faculty and resident physicians' attitudes, perceptions, and knowledge about antimicrobial use and resistance. Infect Control Hosp Epidemiol. 2011;32:714-8.

25. Willems E, Smismans A, Cartuyvels R, Coppens G, van Vaerenbergh K, van den Abeele AM, et al. The preanalytical optimization of blood cultures: a review and the clinical importance of benchmarking in 5 Belgian hospitals. Diagn Microbiol Infect Dis. 2012;73:1-8.

26. Bosk CL, Dixon-Woods M, Goeschel CA, Pronovost PJ. Reality check for checklists. Lancet. 2009;374:444-5.

27. Woolf SH, Grol R, Hutchinson A, Eccles M, Grimshaw J. Potential benefits, limitations, and harms of clinical guidelines. BMJ. 1999;318:527-30.

28. Cockerill FR 3rd, Wilson JW, Vetter EA, Goodman KM, Torgerson CA Harmsen WS, et al. Optimal testing parameters for blood cultures. Clin Infect Dis. 2004:38:1724-30.

29. Gitelis ME, Kaczynski A, Shear T, Deshur M, Beig M, Sefa M, et al. Increasing compliance with the World Health Organization surgical safety checklist - a regional health system's experience. Am J Surg. 2016; https://doi.org/10. 1016/j.amjsurg.2016.07.024.

\section{Submit your next manuscript to BioMed Central and we will help you at every step:}

- We accept pre-submission inquiries

- Our selector tool helps you to find the most relevant journal

- We provide round the clock customer support

- Convenient online submission

- Thorough peer review

- Inclusion in PubMed and all major indexing services

- Maximum visibility for your research

Submit your manuscript at www.biomedcentral.com/submit 